\title{
The needs of family members of patients admitted to the intensive care unit
}

This article was published in the following Dove Medical Press journal:

Patient Preference and Adherence

\author{
Abdalkarem F Alsharari \\ Nursing Department, College of \\ Applied Medical Sciences, Jouf \\ University, Sakakah, Saudi Arabia
}

Correspondence: Abdalkarem F Alsharari Nursing Department, College of Applied Medical Sciences, Jouf University,

Sakakah, Saudi Arabia

Tel +966557470077

Email afalsharari@ju.edu.sa
Purpose: The unanticipated admission of a patient to the intensive care unit (ICU) can be particularly frightening and stressful for their family members. The objective of this study was to identify the most important needs of family members of patients admitted in the ICU and determine their relationship with their sociodemographic characteristics.

Methods: This was a cross-sectional study conducted from April to August 2017 among adult family members of patients admitted to the ICU of four public hospitals in the northern region of Saudi Arabia. The "Critical Care Family Needs Inventory" questionnaire was administered to all consenting relatives of ICU patients in order to determine the family needs. The data were analyzed using descriptive statistics. Also, students' $t$-test and ANOVA were carried out. Results: The most important need identified by the family members was the need for assurance (3.62 \pm 0.44$)$, followed by information (3.47 \pm 0.59$)$, proximity (3.34 \pm 0.44$)$, comfort (3.01 \pm 0.72$)$, and support (2.91 \pm 0.68$)$. A higher level of education was significantly associated with a higher level of need for assurance $(P<0.001)$, information $(P<0.001)$, and proximity $(P<0.001)$. Also, participants who had an unconscious/semiconscious relative in the ICU assigned a higher level of importance to information need $(P<0.001)$ compared with those with a conscious relative. Conclusion: This study has shown that family members of patients admitted to ICU have elevated levels of needs in the assurance, proximity, and information dimensions that require to be addressed. This should guide the development of connection, effective communication, and beneficial cooperation toward offering the best possible care and support to ICU patients and their relatives.

Keywords: nursing care, needs assessment, critical care, family nursing

\section{Introduction}

Family members of patients in the intensive care unit (ICU) encounter psychological crisis, stress, and depression as a result of the admission of their relatives to this unit, which is usually an unanticipated event and meant for individuals in a critical clinical state with the potential for high mortality. ${ }^{1-3}$ A longitudinal study found that about $43 \%$ of the relatives of patients who had been in an ICU had high levels of depressive symptoms a year after discharge. ${ }^{3}$ The clinical condition of the patients in the ICU and their inability to communicate directly with health workers and their family members create anxiety and stress not only about the patients' acute clinical state but also regarding their status during care transitions and the long-term prognosis after discharge. ${ }^{4-6}$ Furthermore, stress due to a relative's illness can affect how family members cope with the condition and thus may hinder the special support that is needed by the patient. ${ }^{7}$ Thus, family members are an integral part of the health care process and management of the well-being of ICU patients. In order to lower the level of anxiety and psychological crisis, the immediate needs of family members of ICU patients should be identified and met. 
The family needs may be considered as the requirements of family members which, if fulfilled, relieve or diminish family distress and, if unmet, may produce distress in family members and the ICU team. ${ }^{8,9}$ Earlier studies in this field evaluated the satisfaction of family members of patients in the ICU with services rendered. ${ }^{8,10-12}$ Some of the studies found that there was a negative effect on family satisfaction as a result of persistent unmet family needs, ${ }^{8,10}$ while others found a high level of satisfaction but with persistent unmet needs. ${ }^{11,12}$ Moreover, a recent study showed that a gap exists between the identified needs of family members visiting intensive care patients and their perceptions of needs as being met or unmet. ${ }^{13}$ Such unmet needs may cause adverse health effects among family members leading to the development of post-intensive care syndrome-family (PICS-F). PICS-F refers to the acute and the chronic psychological effects of critical illness on the family of the patient and includes the symptoms that are experienced by family members during the critical illness as well as those that occur following death or discharge of a loved one from the ICU., ${ }^{9} 14$ Given that the needs of family members of ICU patients may be varied, nurses must be attuned to these needs and must have specific skills in identifying and addressing the needs.

Thus, due to the complexity of care in the ICU which arises not only from the type of care given to the patient, but its impact on the family members, there is a need for a standardized instrument for the identification of the needs of relatives of patients in the ICU. Molter pioneered the early attempts to investigate and characterize these needs and their importance for the families. ${ }^{15}$ Also, in 1983, Molter and Leske developed the first version of the standardized questionnaire "Critical Care Family Needs Inventory (CCFNI)" ${ }^{16,17}$ Currently, this is the most widely used validated instrument to assess and rank the needs of family members of patients in the ICU..$^{16,17}$

The use of this instrument to assess the needs of family members of ICU patients compared with their perceived needs by doctors, ${ }^{18}$ nurses, and hospital social workers has demonstrated a large discordance between needs of relatives of ICU patients and their perceived needs, as health care workers incorrectly identified the most important needs of the family. ${ }^{19,20}$ In 2003, Yin and Lau in Hong Kong showed that the need for reassurance about the expected outcome, perceived to be met by doctors and nurses, is the most identified need by family members. ${ }^{21}$ Furthermore, Chien et al found no differences in the dimensions of the needs of family members with respect to age, educational status, or relationship with the patient. ${ }^{22}$ However, in the US, Obringer et al found that the least important needs of family members were those connected with the dimension of support. ${ }^{23}$ There is now a growing body of evidence on the needs of family members of ICU patients in different parts of the world. ${ }^{18-20,24-40}$

However, despite the increasing evidence, there are currently few studies in Arabic-speaking countries of the Middle East and North African (MENA) region. ${ }^{1,4,5,41}$ This is important because cultural, geographical, and religious contexts could be crucial factors responsible for the variation in family needs by relatives of ICU patients. In addition, the few studies which assessed the needs of family members of ICU patients in the MENA region did not investigate how it varied with their sociodemographic variables. Therefore, the objectives of this study were to identify the most important needs of the family members of patients admitted in the ICU of four public hospitals in Saudi Arabia, and to investigate the relationships between the demographic variables of the patients' relatives and the degree of importance of the dimensions covered by the CCFNI.

\section{Methods \\ Study design}

This was a cross-sectional study conducted from April to August 2017 among family members of patients admitted to the ICU of four public hospitals in the northern region of Saudi Arabia.

\section{Participants and setting}

The four public hospitals were tertiary hospitals with bed capacity that ranges between 200 and 350 beds. The ICUs in each of the hospitals surveyed have subunits (eg, medical, surgical, and coronary care), with bed capacity that ranges between 15 and 32 beds, and a nurse-to-patient ratio of 1:1 to $1: 2$. Unlike other inpatient units, the visiting time for ICU is very limited. A total of 60 minutes a day is only allowed - divided equally into morning and afternoon visits. During this period, the family members are given updates about the clinical condition of the patient.

Eligible family members of patients admitted to the ICUs completed the survey either through a phone interview or by responding to an interviewer-administered questionnaire. The inclusion criteria were: should be an adult (aged above 18 years) family member of a patient admitted to the ICU, the patients must have been admitted in the ICU for at least 48 hours, having visited the patient at least once during their stay in the ICU, and being able to communicate in Arabic. Family members of patients who died in the ICU during the survey period were excluded.

The health system in Saudi Arabia is organized as a large public sector service (provided through the Ministry of 
Health and other government agencies) and a small private sector service. ${ }^{42}$ The Ministry of Health is responsible for the provision of preventive, curative, and rehabilitative health care at primary, secondary, and tertiary care levels to majority of the population in the country. All Saudi nationals and expatriate public sector employees are eligible for a free comprehensive package of health benefits with no requirement for cost sharing. ${ }^{42}$ Most services including critical care, advanced cardiovascular procedures, and cancer care and treatment are covered by the package. Furthermore, there is a Compulsory Employment-Based Health Insurance Scheme paid for by employers which covers private sector expatriate employees. Individuals in this scheme may still incur some costs depending on the insurance level. ${ }^{42}$

\section{Variables}

The main outcome variable assessed was the level of importance of the needs of family members, and this was identified using the CCFNI questionnaire. The other sociodemographic and clinical variables collected from the survey participants were: gender (male/female), educational level (secondary, college, or postgraduate), relationship with the patient (parent/spouse/daughter or son/uncle or aunt/brother or sister/ grandparent), number of visits by the family member to the ICU (one only, 2-3,>3), and level of consciousness of the patient (conscious, semiconscious, unconscious).

\section{Instruments}

The CCFNI questionnaire includes 45 needs that participants rate on a scale from 1 (not important) to 4 (very important). The questions are distributed among five dimensions (ie, assurance, proximity, information, comfort, and support). ${ }^{15,16}$ The psychometric properties of the original version of the CCFNI were assessed in 1991, and it showed a reliability of $(\alpha=0.92)$ for the general scale. ${ }^{16}$ In the original structure of the CCFNI, its five dimensions had an acceptable level of reliability with a reported internal consistency as follows: assurance $(\alpha=0.61)$, support $(\alpha=0.88)$, proximity $(\alpha=0.71)$, comfort $(\alpha=0.75)$, and information $(\alpha=0.78) .{ }^{17}$

The original version of the CCFNI questionnaire was forward-translated to Arabic and back-translated by two independent bilingual experts. Discrepancies were resolved by consensus. The expert-translated CCFNI questionnaire in Arabic was then pre-tested among ten family members of patients in the ICU not used for the survey to ensure language adaptation. The family members assessed the following aspects: clarity of language, concept clarity, wording, and adequate item comprehension. Suggestions obtained from pre-testing were incorporated in the final Arabic version and was also back-translated into English to maintain consistency. The Arabic version of the CCFNI had an excellent reliability with an internal consistency for the general scale of $(\alpha=0.91)$; its five dimensions had a high or an acceptable level of reliability with internal consistency as follows: assurance $(\alpha=0.60)$, support $(\alpha=0.88)$, proximity $(\alpha=0.60)$, comfort $(\alpha=0.68)$, and information $(\alpha=0.80)$.

\section{Sampling and data collection}

The data were collected by the principal investigator (PI) and two nurses who had undergone a standardized training. All eligible family members of patients admitted to the ICU at the time of the survey were invited to participate in the survey. The PI and the two nurses who were trained by the PI invited and recruited the participants. Once a participant verbally agrees to be interviewed, a written informed consent was obtained from them, and they were asked if they wished to be interviewed at the hospital or through phone at a more convenient time. Eligible family members who were not ready for the interview at the ICU at the time of the survey underwent a phone interview to complete the survey. The phone interview at a more convenient time was preferred by some of the clients, especially those who had emotional responses following the very restricted visit they have had to their sick relative in the ICU.

When only one or more than one relative (of the same gender) of an ICU patient was available, only one participant was interviewed, but in situations where more than one relative was available (with different gender) a male relative and a female relative were interviewed.

\section{Data analysis}

The data were entered, cleaned, and analyzed using SPSS version 24 (IBM Corporation, Armonk, NY, USA). Continuous variables were summarized as mean \pm SD and categorical variables as proportions. Categorical variables were summarized using frequency tables and proportions, and the degree to which the family member needs are important was summarized using mean $\pm \mathrm{SD}$. The differences between the average CCFNI dimensions and the sociodemographic variables of the study participants were estimated using the Student's $t$-test and ANOVA. In all cases, a two-sided $P$-value $<0.05$ was considered as the criterion for statistical significance.

\section{Ethics}

The study was conducted in accordance with the Saudi National Committee of Bioethics guidelines. Ethical approval 
was granted by the Committee of Bioethics, Jouf. A written informed consent was obtained from all participants, including those who were interviewed at a later convenient time by phone. A permission to recruit the participants and access to the ICUs was sought from the hospitals. No risks were anticipated, and participation was voluntary and did not interrupt the visiting time allowed to the participants. On-site interviews were conducted outside the ICUs' area at the end of the visit. Those family members who were emotionally affected or did not have time to wait (for the interview) were asked to provide their phone numbers, and were subsequently interviewed by phone on the same or following day of the visit at a convenient time.

\section{Results}

\section{Sociodemographic characteristics of the study participants}

A total of 233 adult family members of ICU patients completed the survey. The sociodemographic characteristics of the family members are shown in Table 1. Overall, 152 $(65.2 \%)$ were male, with 94 (40.3\%) having secondary education. Also, 85 (36.4\%) of the survey participants were either a daughter or a son of the ICU patients, followed by 54 $(23.2 \%)$ who were parents of the patients. Most of the family

Table I Sociodemographic characteristics of family members of intensive care unit patients

\begin{tabular}{|l|l|l|l|}
\hline Variable & Characteristics & $\begin{array}{l}\text { Frequency, } \\
\mathbf{n}\end{array}$ & $\begin{array}{l}\text { Percentage } \\
\text { (\%) }\end{array}$ \\
\hline Gender & Male & 152 & 65.2 \\
\hline & Female & 81 & 34.8 \\
\hline Level of education & Secondary & 94 & 40.3 \\
\hline & College & 76 & 32.6 \\
\hline & Postgraduate & 63 & 27.1 \\
\hline $\begin{array}{l}\text { Relationship to } \\
\text { the patient }\end{array}$ & Parent & 54 & 23.2 \\
\hline & Spouse & 20 & 8.6 \\
\hline & Daughter/son & 85 & 36.4 \\
\hline & Uncle or aunt & 19 & 8.2 \\
\hline & Brother or sister & 20 & 8.6 \\
\hline & Grandparent & 35 & 15.0 \\
\hline Number of visits & $\mathrm{I}$ & 12 & 5.1 \\
\hline & $2-3$ & 157 & 67.4 \\
\hline & $>3$ & 64 & 27.5 \\
\hline $\begin{array}{l}\text { Level of } \\
\text { consciousness }\end{array}$ & Conscious & 30 & 12.9 \\
\hline & Semiconscious & 71 & 30.4 \\
\hline & Unconscious & 132 & 56.7 \\
\hline & & & \\
\hline
\end{tabular}

members have either visited their ICU patients 2-3 times (157 [67.4\%]) or $>3$ times (64 [27.5\%]). At the time of the survey, the family members indicated that $132(56.7 \%)$ of the ICU patients were unconscious, 71 (30.4\%) were semiconscious, and 30 (12.9\%) were conscious.

\section{Most and least important needs of family members of ICU patients}

The overall most important need according to the CCFNI dimensions identified by the family members is the need for assurance (mean 3.62, SD 0.44), followed by information (mean 3.47, SD 0.59), proximity (mean 3.34, SD 0.44), comfort (mean 3.01, SD 0.72), and support (mean 2.91, SD 0.68). Table 2 summarizes the ten most important needs of family members of ICU patients. The results showed that "To be assured that the best care possible is being given to the patient" (mean 3.78, SD 0.63) was ranked first. This was followed by "To feel that the hospital personnel care about the patient" (mean 3.74, SD 0.73). Both of these needs belong to the dimension of assurance, while "To be told about transfer plans while they are being made" (mean 3.72, SD 0.64), which ranked third, belongs to the dimension of proximity.

Table 3 summarizes the majority of needs considered less important by family members of ICU patients. The results showed that "To have another person with you when visiting the critical care unit" (mean 2.54, SD 1.29), "To have good food available in the hospital" (mean 2.33, SD 1.28), and "To have someone to help with financial problems" (mean 2.11, SD 1.23) ranked the lowest. Overall, nine of the ten lowest ranked needs were associated with either support or comfort dimensions (Table 3).

Table 4 shows, in a bivariate analysis, the differences assigned to the different CCFNI dimensions according to sociodemographic characteristics of the family members of ICU patients. Men assigned a higher level of importance to all the dimensions except proximity; however, the gender differences in the dimensions were not statistically significant $(P>0.05)$. Also, significant differences were found in the level of importance assigned for assurance $(P<0.001)$, proximity $(P<0.001)$, and information $(P<0.001)$ dimensions according to the educational level of the participants. Furthermore, significant differences were found in the level of importance assigned to all of the dimensions $(P<0.001)$ except assurance according to the relationship of the survey participants with the ICU patients; participants with a higher level of relationship (first-degree relatives) tended to assign a higher need for these dimensions. No differences were detected in the level of importance assigned to the various dimensions according 
Table 2 Mean and SD of the ten most important needs of family members of intensive care unit patients, according to the CCFNI

\begin{tabular}{|l|l|l|l|}
\hline CCFNI rank & Need & Dimension & Mean \pm SD score \\
\hline I & To be assured that the best care possible is being given to the patient & Assurance & $3.78 \pm 0.63$ \\
\hline 2 & To feel that the hospital personnel care about the patient & Assurance & $3.74 \pm 0.73$ \\
\hline 3 & To be told about transfer plans while they are being made & Proximity & $3.72 \pm 0.64$ \\
\hline 4 & To know the expected outcome & Assurance & $3.69 \pm 0.85$ \\
\hline 5 & To know why things were done for the patient & Information & $3.68 \pm 0.75$ \\
\hline 6 & To be called at home about changes in the patient's condition & Proximity & $3.67 \pm 0.8$ I \\
\hline 7 & To know specific facts concerning the patient's progress & Assurance & $3.63 \pm 0.78$ \\
\hline 8 & To see the patient frequently & Proximity & $3.62 \pm 0.8$ I \\
\hline 9 & To feel there is hope & Assurance & $3.57 \pm 0.90$ \\
\hline 10 & To have a specific person to call at the hospital when unable to visit & Information & $3.56 \pm 0.79$ \\
\hline
\end{tabular}

Abbreviation: CCFNI, Critical Care Family Needs Inventory.

to the number of times the participants visited their relatives in the ICU. However, participants who had an unconscious/semiconscious relative in the ICU assigned a higher level of importance to information dimension $(P<0.001)$ compared with those with a conscious relative (Table 4$)$.

\section{Discussion}

One of the core responsibilities of nurses in the ICUs is to attend to the needs of patients and their family members. These priority needs of family members of ICU patients differ according to sociocultural contexts. ${ }^{24}$ In this study, we found that five of the top ten needs identified by family members of ICU patients in Saudi Arabia fell within the assurance dimension. This is consistent with previous studies carried out in Greece, ${ }^{25}$ Malaysia, ${ }^{26}$ Jordan, ${ }^{27}$ Iran, ${ }^{28}$ Australia, ${ }^{29}$ Spain, ${ }^{30} \mathrm{Nepal}$, and Brazil as well as a review of 15 studies by Fortunatti, ${ }^{31-33}$ which demonstrated that assurance needs were perceived as a greater need by the family members. In particular, the assurance need "To be assured that the best care possible is being given to the patient" was ranked first. This was consistent with the findings of an earlier study in Jeddah and other Arab nations, ${ }^{26-28,34}$ but differs from the findings in Europe and South America which showed that "To have questions answered honestly" as the most ranked assurance need. ${ }^{25,29-32,35}$ The reason for the differences between settings is not clear, but it suggests that sociocultural values may play a role, and these items should receive more attention during counseling of family members by ICU nurses. ${ }^{34}$

In this study, nine of the least important needs of the family members of ICU patients fell under the dimensions of comfort and support. Although the needs for support and comfort were considered less important by family members, some of these needs' items had a score of 3 or more. As demonstrated elsewhere, ${ }^{35}$ this suggests that these dimensions of need are still important to the family members, although to a lesser extent. In particular, "To have someone to help with financial problems" and "To have good food available in the hospital" were the least important needs of the family

Table 3 Mean and SD of the ten least important needs of family members of intensive care unit patients, according to the CCFNI

\begin{tabular}{|l|l|l|l|}
\hline CCFNI rank & Need & Dimension & Mean \pm SD score \\
\hline I & To have someone to help with financial problems & Support & $2.1 \mathrm{I} \pm \mathrm{I} .23$ \\
\hline 2 & To have good food available in the hospital & Comfort & $2.33 \pm I .28$ \\
\hline 3 & To have another person with you when visiting the critical care unit & Support & $2.54 \pm I .29$ \\
\hline 4 & To be alone at any time & Support & $2.55 \pm I .23$ \\
\hline 5 & To have a telephone near the waiting room & Comfort & $2.66 \pm I .35$ \\
\hline 6 & To be told about someone to help with family problems & Support & $2.67 \pm I .14$ \\
\hline 7 & To have a place to be alone while in the hospital & Support & $2.67 \pm I .15$ \\
\hline 8 & To talk to the same nurse every day & Proximity & $2.78 \pm I .09$ \\
\hline 9 & To have friends nearby for support & Support & $2.8 I \pm 1.24$ \\
\hline 10 & To feel it is alright to cry & Support & $2.85 \pm I .20$ \\
\hline
\end{tabular}

Abbreviation: CCFNI, Critical Care Family Needs Inventory. 
Table 4 Differences in mean $( \pm S D)$ between the scores of the CCFNI dimensions according to sociodemographic characteristics of the participants

\begin{tabular}{|c|c|c|c|c|c|}
\hline Variable & Comfort & Assurance & Proximity & Information & Support \\
\hline \multicolumn{6}{|l|}{ Gender } \\
\hline Male & $3.06 \pm 0.73$ & $3.63 \pm 0.35$ & $3.32 \pm 0.39$ & $3.47 \pm 0.60$ & $2.93 \pm 0.75$ \\
\hline Female & $2.92 \pm 2.92$ & $3.62 \pm 0.57$ & $3.37 \pm 0.54$ & $3.47 \pm 0.57$ & $2.89 \pm 0.55$ \\
\hline$t$-statistic $(P$-value*) & $1.47(0.142)$ & $0.06(0.860)$ & $0.62(0.433)$ & $0.10(0.919)$ & $0.27(0.603)$ \\
\hline \multicolumn{6}{|l|}{ Education } \\
\hline Secondary & $2.99 \pm 0.87$ & $3.70 \pm 0.29$ & $3.49 \pm 0.39$ & $3.47 \pm 0.76$ & $2.80 \pm 0.83$ \\
\hline College & $2.87 \pm 0.6 \mathrm{I}$ & $3.39 \pm 0.66$ & $3.14 \pm 0.53$ & $3.23 \pm 0.64$ & $3.05 \pm 0.51$ \\
\hline Postgraduate & $3.13 \pm 0.62$ & $3.72 \pm 0.27$ & $3.35 \pm 0.37$ & $3.62 \pm 0.27$ & $2.92 \pm 0.68$ \\
\hline$F$-statistic ( $P$-value $)$ & $2.62(0.075)$ & $13.91(<0.001)$ & $12.27(<0.00 \mathrm{I})$ & $9.03(<0.001)$ & $2.83(0.06 \mathrm{I})$ \\
\hline \multicolumn{6}{|l|}{ Relationship } \\
\hline Parent & $3.17 \pm 0.58$ & $3.72 \pm 0.42$ & $3.61 \pm 0.36$ & $3.8 I \pm 0.25$ & $3.25 \pm 0.47$ \\
\hline Spouse & $2.83 \pm 0.40$ & $3.50 \pm 0.75$ & $3.38 \pm 0.63$ & $3.68 \pm 0.65$ & $2.67 \pm 0.40$ \\
\hline Daughter/son & $2.83 \pm 0.86$ & $3.62 \pm 0.45$ & $3.26 \pm 0.4 \mathrm{I}$ & $3.3 I \pm 0.64$ & $2.72 \pm 0.73$ \\
\hline Uncle/aunt & $3.13 \pm 0.16$ & $3.53 \pm 0.64$ & $3.02 \pm 0.18$ & $3.25 \pm 0.27$ & $3.04 \pm 0.72$ \\
\hline Brother/sister & $2.73 \pm 1.05$ & $3.44 \pm 0.45$ & $3.37 \pm 0.54$ & $2.86 \pm-0.86$ & $2.87 \pm 0.92$ \\
\hline Grandparent & $3.40 \pm 0.25$ & $3.69 \pm 0.27$ & $3.25 \pm 0.37$ & $3.67 \pm 0.20$ & $2.92 \pm 0.63$ \\
\hline$F$-statistic ( $P$-value $)$ & $5.04(<0.001)$ & $1.89(0.097)$ & $7.7 \mathrm{I}(<0.00 \mathrm{I})$ & $13.69(<0.001)$ & $5.03(<0.001)$ \\
\hline \multicolumn{6}{|l|}{ Number of visits } \\
\hline I & $3.18 \pm 0.68$ & $3.60 \pm 0.25$ & $3.32 \pm 0.44$ & $3.61 \pm 0.25$ & $2.89 \pm 0.81$ \\
\hline $2-3$ & $3.0 \mathrm{I} \pm 0.67$ & $3.65 \pm 0.42$ & $3.36 \pm 0.42$ & $3.45 \pm 0.59$ & $2.84 \pm 0.69$ \\
\hline$>3$ & $2.98 \pm 0.82$ & $3.56 \pm 0.5 \mathrm{I}$ & $3.30 \pm 0.5 \mathrm{I}$ & $3.48 \pm 0.65$ & $3.08 \pm 0.62$ \\
\hline$F$-statistic ( $P$-value $)$ & $0.39(0.680)$ & $0.88(0.417)$ & $0.43(0.653)$ & $0.42(0.659)$ & $2.91(0.057)$ \\
\hline \multicolumn{6}{|l|}{ Consciousness level } \\
\hline Conscious & $2.76 \pm 1.09$ & $3.48 \pm 0.77$ & $3.18 \pm 0.77$ & $3.04 \pm 1.06$ & $2.92 \pm 0.88$ \\
\hline Semiconscious & $3.08 \pm 0.64$ & $3.66 \pm 0.32$ & $3.35 \pm 0.39$ & $3.54 \pm 0.40$ & $2.8 I \pm 0.75$ \\
\hline Unconscious & $3.03 \pm 0.64$ & $3.63 \pm 0.39$ & $3.37 \pm 0.36$ & $3.52 \pm 0.49$ & $2.96 \pm 0.59$ \\
\hline F-statistic ( $P$-value $)$ & $1.01(0.101)$ & $1.89(0.154)$ & $2.35(0.097)$ & $9.46(<0.00 \mathrm{I})$ & $1.24(0.293)$ \\
\hline
\end{tabular}

Note: ${ }^{*} P$-value is based on Student's $t$-test, and others are based on ANOVA.

Abbreviation: CCFNI, Critical Care Family Needs Inventory.

members. This was consistent with studies elsewhere, ${ }^{24,35}$ and suggests that there is a high level of financial risk protection for health care services in the study area as well as reduced need for food among relatives of patients in the ICU. Moreover, if the hospital was close to the families' homes, they may not need to eat at the hospital, making the quality of the hospital's food less relevant.

There was no gender difference in the needs of the participants in this study. This contrasts with the experience in Chile, Norway, and South Africa where women tended to have a higher level of need compared to men. ${ }^{35-37}$ The reasons for this difference may be due to the inclusion of a smaller proportion of women in this survey, probably due to religious and cultural reasons. This might have influenced the high rating of needs, as previous studies have shown that females consider and report family needs as more important than their male counterparts..$^{35,37-39}$ These gender differences in ranking majority of needs suggest that it may be necessary for health care workers to exercise tact and be sensitive to the needs of family members of ICU patients, especially in situations where females form the highest proportion of family members. This is to ensure that strategies are adopted to satisfy the differing but important needs of these women.

Family members with a higher level of education considered assurance, proximity, and information dimensions to be significantly more important compared with those with a lower level of education. It could be that family members with a higher level of education were able to seek better information about the patient's condition, diagnosis, and management in the ICU, and obtain assurances of the 
various trajectories of their relative's illness leading to reduction in anxiety among family members and ensured that they maintained proximity with them as they are being managed in the ICU. In addition, higher education not only helps people to ask better questions but it also helps them to better understand the information that is given to them. However, there were no differences in the comfort and support dimensions according to the level of education of the participants, which points to high level of accessibility to health care services in the setting. These findings disagree with the report of Padilla-Fortunatti et al, ${ }^{35}$ which may probably be due to differences in educational attainment in the study participants and accessibility to health services between the two settings.

Parents of the ICU patients tended to have the highest needs for assurance, proximity, information, and support dimensions, but less so for comfort dimension compared to any other family member. This may be due to the biological affinities they have with their children. This was partly demonstrated by other researchers. ${ }^{35}$ The number of visits to the ICU to see their relatives did not significantly affect their needs for any of the dimensions. However, participants with an unconscious relative in the ICU significantly had a higher need within the information dimension. It is possible that the higher need for information among family members having a comatose loved one in the ICU was because they are not getting any responses from the patient. As a result, they want to be kept abreast with any developments regarding their relatives in the ICU.

With the five dimensions structure, the Arabic version of the CCFNI tool, like the main version of the tool, seems to have a high face validity in identifying the needs of relatives of individuals admitted in the ICU. Also, it appears that the experts who participated in the forward and backward translation of the tool used the right conceptual equivalent of words or phrases to capture the right meaning of local and contextual issues in the tool in order to maintain its content validity, which has been established in previous studies. ${ }^{38,43}$ However, further studies are needed to evaluate the construct validity and reliability of the Arabic version of the CCFNI tool.

The present study has some strengths and limitations. A key strength is that it was carried out among participants from "four public hospitals", so the findings may be fairly representative of the findings in the setting. Also, the relatively high sample size, which allowed some advanced analysis to be performed according to the participants' demographic characteristics, was another major strength of the study. However, this study has some limitations. First, this was a cross-sectional study which does not allow making any causal inference. The differing illnesses of the ICU patients were not assessed - the survey participants might have varied their needs based on the type and severity of illness of their relatives. In addition, data were collected from more than one family member of some of the patients. For such participants, it is likely that their concerns may be highly correlated. This effect was reduced by conducting the interview separately for the participants in a private room. This study compared the needs of family members in four public health facilities. A study that compared the needs of family members in public and private facilities found significant differences in their needs according to the type of facility. ${ }^{40}$ Thus, the current findings might not represent the needs of family members of ICU patients in private facilities. These variations and their interrelationships should be explored in future studies.

\section{Conclusion}

This study has shown that family members of patients admitted to ICU have elevated levels of needs in the assurance, proximity, and information dimensions that should be addressed. In addition, the family members had the lowest level of needs in the comfort and support dimensions. Also, the various dimensions of the needs varied according to the sociodemographic characteristics of the participants. The identification of the dimensions of different needs of the family members is crucial for the development of connection, effective communication, and beneficial cooperation toward offering the best possible care and support to ICU patients and their relatives. Future studies should consider describing these differing cultural, demographic, and contextual aspects of the needs of family members of patients admitted in the ICU, as well as assess if these factors vary with time, patient's illness type, and their clinical status.

\section{Acknowledgments}

I would like to thank all the participants for their time. Also, I would like to thank all health workers in the study hospitals for their support.

\section{Disclosure}

The author reports no conflicts of interest in this work.

\section{References}

1. Azoulay E, Pochard F, Chevret S, et al. Meeting the needs of intensive care unit patient families: a multicenter study. Am J Respir Crit Care Med. 2001;163:135-139. doi:10.1164/ajrccm.163.1.2005117

2. Chui WY, Chan SW. Stress and coping of Hong Kong Chinese family members during a critical illness. J Clin Nurs. 2007;16:372-381. doi:10. 1111/j.1365-2702.2005.01461.x 
3. Cameron JI, Chu LM, Matte A, et al. One-year outcomes in caregivers of critically ill patients. N Engl J Med.2016;374:1831-1841. doi:10.1056/ NEJMoa1511160

4. Tsai PC, Yip PK, Tai JJ, Lou MF. Needs of family caregivers of stroke patients: a longitudinal study of caregivers' perspectives. Patient Prefer Adherence. 2015;9:449-457. doi:10.2147/PPA.S77713

5. Jeffs L, Saragosa M, Law MP, Kuluski K, Espin S, Merkley J. The role of caregivers in interfacility care transitions: a qualitative study. Patient Prefer Adherence. 2017;11:1443-1450. doi:10.2147/PPA.S136058

6. Jeffs L, Kitto S, Merkley J, Lyons RF, Bell CM. Safety threats and opportunities to improve interfacility care transitions: insights from patients and family members. Patient Prefer Adherence. 2012;6: 711-718. doi:10.2147/PPA.S36797

7. Lee LY, Lau YL. Immediate needs of adult family members of adult intensive care patients in Hong Kong. J Clin Nurs. 2003;12:490-500.

8. Khalaila R. Patients' family satisfaction with needs met at the medical intensive care unit. J Adv Nurs. 2013;69:1172-1182. doi:10.1111/ j.1365-2648.2012.06109.x

9. Davidson JE, Aslakson RA, Long AC, et al. Guidelines for familycentered care in the neonatal, pediatric, and adult ICU. Crit Care Med. 2017;45(1):103-128. doi:10.1097/CCM.0000000000002169

10. Davidson JE, Daly BJ, Agan D, Brady NR, Higgins PA. Facilitated sensemaking: a feasibility study for the provision of a family support program in the intensive care unit. Crit Care Nurs Q. 2010;33(2):177-189. doi:10.1097/CNQ.0b013e3181d91369

11. Auerbach SM, Kiesler DJ, Wartella J, Rausch S, Ward KR, Ivatury R. Optimism, satisfaction with needs met, interpersonal perceptions of the healthcare team, and emotional distress in patients' family members during critical care hospitalization. Am J Crit Care. 2005;14:202-2010.

12. Clark K, Milner KA, Beck M, Mason V. Measuring family satisfaction with care delivered in the intensive care unit. Crit Care Nurse. 2016;36: e8-e14. doi:10.4037/ccn2016276

13. Nolen KB, Warren NA. Meeting the needs of family members of ICU patients. Crit Care Nurs Q. 2014;37:393-406. doi:10.1097/CNQ. 0000000000000040

14. Rawal G, Yadav S, Kumar R. Post-intensive care syndrome: an overview. J Transl Int Med. 2017;5(2):90-92. doi:10.1515/jtim-2016-0016

15. Molter NC. Needs of relatives of critically ill patients: a descriptive study. Heart Lung. 1979;8:332-339.

16. Molter N, Leske JS. Critical care family needs inventory. 1983. Available from: www.uwm.edu/nursing/wp-content/uploads/ sites/287/2015/05/Lesketool.pdf. Accessed December 16, 2018.

17. Leske JS. Internal psychometric properties of the critical care family needs inventory. Heart Lung. 1991;20:236-244.

18. Hinkle JL, Fitzpatrick E. Needs of American relatives of intensive care patients: perceptions of relatives, physicians and nurses. Intensive Crit Care Nurs. 2011;27:218-225. doi:10.1016/j.iccn.2011.04.003

19. Maxwell KE, Stuenkel D, Saylor C. Needs of family members of critically ill patients: a comparison of nurse and family perceptions. Heart Lung. 2007;36:367-376. doi:10.1016/j.hrtlng.2007.02.005

20. Kinrade T, Jackson AC, Tomnay J. Social workers' perspectives on the psychosocial needs of families during critical illness. Soc Work Health Care. 2011;50:661-681. doi:10.1080/00981389.2011.590874

21. Lee IY, Chien WT, MacKenzie AE. Needs of families with a relative in a critical care unit in Hong Kong. J Clin Nurs. 2000;9:46-54.

22. Chien W-T, Ip W-Y, Lee IYM. Psychometric properties of a Chinese version of the critical care family needs inventory. Res Nurs Health. 2005;28(6):474-487. doi:10.1002/(ISSN)1098-240X

23. Obringer K, Hilgenberg C, Booker K. Needs of adult family members of intensive care unit patients. J Clin Nurs. 2012;21:1651-1658. doi:10. 1111/j.1365-2702.2011.03989.x

24. Bandari R, Heravi-Karimooi M, Rejeh N, Mirmohammad Khani M, Vaismoradi M, Snelgrove S. Information and support needs of adult family members of patients in intensive care units: an Iranian perspective. J Res Nurs. 2015;20:401-422. doi:10.1177/17449887115591868
25. Chatzaki M, Klimathianaki M, Anastasaki M, Chatzakis G, Apostolakou E, Georgopoulos D. Defining the needs of ICU patient families in a suburban/rural Greek population: a prospective cohort study. J Clin Nurs. 2012;21:1831-1839. doi:10.1111/j.1365-2702.2011. 04022. $\mathrm{x}$

26. Noor Siah AA, Ho SE, Jafaar MZ, et al. Information needs of family members of critically ill patients in intensive care unit of a tertiary hospital. Clin Ter. 2012;163:63-67.

27. Omari FH. Perceived and unmet needs of adult Jordanian family members of patients in ICUs. J Nurs Scholarsh. 2009;41:28-34. doi:10. 1111/j.1547-5069.2009.01248.x

28. Shorofi SA, Jannati Y, Moghaddam HR, Yazdani-Charati J. Psychosocial needs of families of intensive care patients: perceptions of nurses and families. Niger Med J. 2016;57:10-18. doi:10.4103/0300-1652.180557

29. Kinard T, Jackson AC, Tomnay JE. The psychosocial needs of families during critical illness: comparison of nurses' and family members' perspectives. Aust J Adv Nurs. 2009;27:82-88.

30. Bijttebier P, Vanoost S, Delva D, Ferdinande P, Frans E. Needs of relatives of critical care patients: perceptions of relatives, physicians and nurses. Intensive Care Med. 2001;27:160-165.

31. Khatri Chhetri I, Thulung B. Perception of nurses on needs of family members of patient admitted to critical care units of teaching hospital, Chitwan Nepal: a cross-sectional institutional based study. Nurs Res Pract. 2018;2018:1369164.

32. Lucchese AC, Citero Vde A, De Marco MA, Andreoli SB, NogueiraMartins LA. The needs of members of the families of general hospital inpatients. Sao Paulo Med J. 2008;126:128-131.

33. Fortunatti CF. Most important needs of family members of critical patients in light of the critical care family needs inventory. Invest Educ Enferm. 2014;32:306-316. doi:10.17533/udea.iee.v32n2a13

34. de Beer J, Alnajjar H, Elarousy W, Al-Mowalled SZ. Describing nurse's, doctor's and family members' perceptions on family needs in critical care units at King Khalid Hospital-Jeddah, Saudi Arabia. Nur Primary Care. 2017;1:1-7.

35. Padilla-Fortunatti C, Rojas-Silva N, Amthauer-Rojas M, MolinaMuñoz Y. Needs of relatives of critically ill patients in an academic hospital in Chile. Enferm Intensiva. 2018;29:32-40. doi:10.1016/j.enfi. 2017.09.001

36. Høghaug G, Fagermoen MS, Lerdal A. The visitor's regard of their need for support, comfort, information proximity and assurance in the intensive care unit. Intensive Crit Care Nurs. 2012;28:263-268. doi:10. 1016/j.iccn.2011.11.009

37. Brysiewicz P, Chipps J. A survey of next of kin needs of trauma patients admitted to intensive care units in South Africa. Intensive Crit Care Nurs. 2017;43:136-142. doi:10.1016/j.iccn.2017.07.009

38. Bijttebier P, Delva D, Vanoost S, Bobbaers H, Lauwers P, Vertommen H. Reliability and validity of the critical care family needs inventory in a dutch-speaking Belgian sample. Heart Lung. 2000;29:278-286. doi:10. 1067/mhl.2000.107918

39. Kynoch K, Chang A, Coyer F, McArdle A. Developing a model of factors that influence meeting the needs of family with a relative in ICU. Int J Nurs Pract. 2018:e12693. Epub ahead of print. doi:10.1111/ijn. 12693

40. Freitas KS, Kimura M, Ferreira KA. Family members' needs at intensive care units: comparative analysis between a public and a private hospital. Rev Lat Am Enfermagem. 2007;15:84-92.

41. Al-Mutair AS, Plummer V, Clerehan R, O'Brien AT. Families' needs of critical care Muslim patients in Saudi Arabia: a quantitative study. Nurs Crit Care. 2014;19:185-195. doi:10.1111/nicc.12039

42. Almalki M, FitzGerald G, Clark M. Health care system in Saudi Arabia: an overview. East Mediterr Health J. 2011;17(10):784-793. doi:10. 26719/2011.17.10.784

43. Macey BA, Bouman CC. An evaluation of validity, reliability, and readability of the critical care family needs inventory. Heart Lung. 1991;20:398-403. 
Patient Preference and Adherence

Dovepress

\section{Publish your work in this journal}

Patient Preference and Adherence is an international, peer-reviewed, open access journal that focuses on the growing importance of patient preference and adherence throughout the therapeutic continuum. Patient satisfaction, acceptability, quality of life, compliance, persistence and their role in developing new therapeutic modalities and compounds to optimize clinical outcomes for existing disease states are major areas of interest for the journal. This journal has been accepted for indexing on PubMed Central. The manuscript management system is completely online and includes a very quick and fair peer-review system, which is all easy to use. Visit http://www. dovepress.com/testimonials.php to read real quotes from published authors.

Submit your manuscript here: http://www.dovepress.com/patient-preference-and-adherence-journal 